\title{
Dry Liberation of Fungus Spores by Raindrops
}

\author{
By J. M. HIRST and O. J. STEDMAN \\ Rothamsted Experimental Station, Harpenden, Hertfordshire
}

SUMMARY

Large transient increases in the concentration of some dry airborne spores coincident with the start of rain suggested that the first raindrops to wet surfaces might disperse spores other than in splash droplets or by wetting fructifications. Experimental collisions between glass beads or water drops and spore-bearing surfaces showed that both rapid air movement in advance of radially spreading splashes and vibration can suspend spores in air. Removal by air movement is most effective when large drops collide with surfaces carrying spores that are loose or raised above the surface.

\section{INTRODUCTION}

There are already three accepted ways in which rain influences the air spora. One, falling raindrops remove spores from suspension in the air, with an efficiency that depends on the dimensions of the spores, the diameters of the drops and the ease with which the spore surface is wetted (May, 1958; Davies, 1961). Although plant pathologists have neglected this 'rain-scrubbing' or 'wash-out' of particles from the air it is probably the most effective mechanism for depositing small particles (Hirst, 1959). Two, when raindrops collide with wet, spore-bearing surfaces, parts of the falling drop and the surface water film become incorporated in splash droplets that contain spores. Many plant pathogens are thus 'splash dispersed', but the process probably adds little to the number of airborne spores because most splash droplets are large and soon deposited (Gregory, Guthrie \& Bunce, 1959). Three, wetting fructifications can initiate spore release, for example, ascospores are released by hydrostatic pressure (Ingold, 1953).

Evidence from spore trapping suggests that, when rain starts, there are often large transient increases in the numbers of some dry spores in air. Published reports mention Cladosporium sp. (Ainsworth, 1952 ; Gregory, 1954 ; Hirst, 1953, 1959 ; Rich \& Waggoner, 1962), Ustilago nuda (Sreeramulu, 1962), Pithomyces chartarum (Meredith, 1962). Similar increases can accompany watering in glasshouses (Hirst, 1959). Our work shows that such increases could occur when the first drops of rain strike dry plant surfaces but does not disprove other suggested explanations (Ainsworth, 1952; Hirst, 1953; Gregory, 1954).

\section{APPARATUS}

The effects of water-drops colliding at terminal velocity with spore-bearing surfaces ('targets') were studied using a tripod ladder (Pl. 1, fig. 1) $25 \mathrm{ft}$. (7.6 m.) tall, fitted with a central vertical pipe $2 \cdot 4$ in. $(6 \cdot 0 \mathrm{~cm}$.) diam. down which waterdrops could be aimed accurately. The targets were placed within a vertical glass cylinder $5 \frac{1}{2}$ in. (14 cm.) diam. and 8 in. $(20 \mathrm{~cm}$.) high (Pl. 1, fig. 2$)$. To delay removal, by the wind, of any spores liberated, the top of the cylinder was closed by a loose panel except for a 2 in. $(5 \cdot 1 \mathrm{~cm}$.) diam. central hole through which the drops fell. 
A small stationary-slide impactor (Gregory, 1954) was used to sample air within the sampling cylinder at $10 \mathrm{l} . / \mathrm{min}$. with its $2 \times 14 \mathrm{~mm}$. orifice directed tangentially half way up the wall of the cylinder. In some tests microscope slides coated with naphthol green B in gelatine (Liddell \& Wootten, 1957) were exposed inside the cylinder to test whether spores were dispersed in splash droplets. Whenever possible the tests were standardized, and each comprised three 5 min. (50 1.) air samples, taken before, during and after the period when water-drop collisions occurred. The number of collisions had to be varied according to the density of spores on the targets. In some early tests collisions were continued throughout the $5 \mathrm{~min}$. period, but in later tests 10 collisions at the beginning of the period was adopted as a standard. With some plant material only one drop could be used without making spore deposits uncountable. The large $(5.0 \mathrm{~mm}$.) drops were formed at the end of a glass tube, and smaller ones (3.0 and $\mathbf{2} \cdot 0 \mathrm{~mm}$.) at the end of a hypodermic syringe needle, the rate of dropping was controlled by a tap.

\section{RESULTS}

\section{Preliminary tests}

Water-drop collisions on wheat straws rusted by Puccinia graminis (Table 1 and Hirst, 1961) showed that, although some spores were splash-dispersed to the inner wall of the sampling cylinder ( $\mathrm{Pl}$. 1, fig. 2), most spores caught in the impactors were dispersed dry, a fact demonstrated by loading the impactor with slides coated with naphthol green B in gelatine and then over-coating, with 'Vaseline', one half of the area to be exposed beneath the orifice. Before counting, these slides were mounted in liquid paraffin. Uredospores arriving in water droplets were retained within characteristic stain-cleared circles on the gelatine area but few dry uredospores were caught on this half (Hirst, 1961 and Pl. 2, fig. 3). The portion coated with 'Vaseline' caught many more spores, for it retained those that arrived either dry or in droplets.

Tests in which $3.0 \mathrm{~mm}$. diam. glass beads were dropped on rusted wheat straws stapled on cards, confirmed that mechanical shock accounted for much of the release (Table 1, A, B). Exposing the same straws later to $\mathbf{3 \cdot 4} \mathbf{m m}$. water-drops released further spores from the part-exhausted specimens (Table 1, B). Halfembedding straws in wax (Table 1, C, D) decreased the number released by falling water-drops or beads, but subsequent exposure, to water-drops, of the specimens first exposed to beads resulted in a proportionally greater increase. This suggested that water-drops might have some other action besides mechanical shaking. Exposure of rusted straws taped securely to flexible plastic strips (pot labels) firmly clamped at one end (Table 1, E) showed that, when $3.4 \mathrm{~mm}$. drops fell on straws on the upper surface of the strip, they released more spores than when the strip was inverted and the drops collided with the strip and the straws were underneath. This could have resulted from the joint action of shock and some other effect with straws uppermost (Table 1, E2) compared to the effect of shock alone, probably diminished when the straws were below (Table 1, E4). These phenomena were investigated in tests with Lycopodium clavatum spores $32 \mu$ diam. uniformly deposited on inert surfaces.

Radial flow in the spreading drop after collision seemed another possible force. 
Engel (1955) studied the impact of large (about $5 \cdot 7 \mathrm{~mm}$. diam.) drops falling at terminal velocity on inelastic surfaces, in connexion with the rain erosion of metals forming the skin of high-speed aircraft. After collision, drops spread radially on the surface up to $2 \cdot 3 \mathrm{~cm}$. radius, the whole process being completed in about 2 msec. The terminal velocity of the drops was $26.9 \mathrm{ft}$. $/ \mathrm{sec}$. $(820 \mathrm{~cm}$. $/ \mathrm{sec}$.). Momentarily in the first stages of collision the velocity of radial flow reached $8 \cdot 6$ times the terminal velocity and exceeded it until the drop was greater than $1 \mathrm{~cm}$. in radius. Such rapid movement must disturb air within the laminar boundary layer and could transfer spores into turbulent air where they would be dispersed by the more usual processes of eddy diffusion.

Table 1. Estimated total catch of Puccinia graminis uredospores in 50 l. air sample in preliminary tests (see text)

\begin{tabular}{|c|c|c|c|c|}
\hline Sample & $\begin{array}{c}\text { (1) } \\
\text { Before } \\
\text { dropping }\end{array}$ & $\begin{array}{l}(2) \\
\text { First } \\
\text { dropping }\end{array}$ & $\begin{array}{c}\text { (3) } \\
\text { After } \\
\text { dropping }\end{array}$ & $\begin{array}{c}\text { (4) } \\
\text { Second } \\
\text { dropping }\end{array}$ \\
\hline \multicolumn{5}{|l|}{ Treatment } \\
\hline A. 9 horizontal straws on card, $3 \cdot 4 \mathrm{~mm}$. drops & 56 & $\begin{array}{l}\text { Water, } \\
12,130\end{array}$ & 2 & - \\
\hline $\begin{array}{l}\text { B. } 9 \text { horizontal straws on card, } 3 \mathrm{~mm} \text {. beads } \\
\text { then } 3.4 \mathrm{~mm} \text {. drops }\end{array}$ & 20 & $\begin{array}{l}\text { Beads, } \\
11,918\end{array}$ & 1 & $\begin{array}{l}\text { Water, } \\
843\end{array}$ \\
\hline $\begin{array}{l}\text { C. } 9 \text { horizontal straws part embedded in wax, } \\
3 \cdot 4 \mathrm{~mm} \text {. drops }\end{array}$ & 3 & $\begin{array}{r}\text { Water, } \\
573\end{array}$ & 4 & - \\
\hline $\begin{array}{l}\text { D. } 9 \text { horizontal straws part embedded in wax, } \\
3 \mathrm{~mm} \text {. beads then } 3 \cdot 4 \mathrm{~mm} \text {. drops }\end{array}$ & - & $\begin{array}{r}\text { Beads, } \\
2429\end{array}$ & 一 & $\begin{array}{l}\text { Water, } \\
\mathbf{7 5 5}\end{array}$ \\
\hline $\begin{array}{l}\text { E. } 3 \text { horizontal straws taped to pot label, } \\
3.4 \mathrm{~mm} \text {. drops }\end{array}$ & - & $\begin{array}{c}\text { Water } \\
\text { Straws up, } \\
629\end{array}$ & - & $\begin{array}{c}\text { Water } \\
\text { Straws down, } \\
39\end{array}$ \\
\hline
\end{tabular}

\section{Tests with Lycopodium spores}

To assess the relative importance of these processes, it was necessary to have a series of reproducible deposits, each of a uniform density of dry spores and, at least in some tests, on surfaces resistant to mechanical shaking. Accordingly Lycopodium clavatum spores (32 $\mu$ diam.) were deposited uniformly (average density 700 spores/ $\mathrm{mm} .{ }^{2}$ ) by quickly blowing a standard volume of spores into suspension at the top of a $5 \frac{1}{2} \times 16 \mathrm{in}$. $(14 \times 40 \mathrm{~cm}$.) vertical cylinder and allowing them to sediment on either of two kinds of test surfaces. A cylindrical iron block 4.9 in. $(12.5 \mathrm{~cm}$.) diam., $1.5 \mathrm{in} .(3.8 \mathrm{~cm}$.) high and weighing $8 \cdot 5 \mathrm{lb} .(3.86 \mathrm{~kg}$.) was used as anstacle immovable and inelastic to water-drops. Celluloid discs of the same diameter but $0.012 \mathrm{in} .(0.30 \mathrm{~mm}$.) thick were rested on short mown grass to represent uniformly supported but slightly elastic targets. Between tests the block was washed and degreased; discs were washed and dried with a clean cloth in the first series of tests; in the second series, they were washed and treated with 'Cirrasol' on both surfaces to remove electrostatic charges.

In the first series of tests, air samples were taken to measure the effects of collisions by glass beads $(3.5 \mathrm{~mm}$. diam.) and water-drops of 2.4 and $5.2 \mathrm{~mm}$. diam. In volume these were related as $1: 0 \cdot 32: 3 \cdot 27$ but in mass as $1: 0 \cdot 13: 1 \cdot 31$. In kinetic energy the glass bead was therefore reasonably similar to the larger water-drop. Table 2 shows that the large drop liberated between 6 and 10 times as many spores as the smaller, and that both released more from the inelastic surface than from the 
elastic, presumably because some energy was wasted in locally depressing the celluloid. By contrast, beads liberated very few spores from the block, which they could not shake and deform as they could the celluloid disc. After applying 'Cirrasol', similar results were obtained but the catches were much smaller throughout, probably because some sticky 'Cirrasol' film remained. The results suggest that electrostatic forces were not important in determining the results of the first series. Photographs of Lycopodium deposits after collision show some of these effects clearly. The glass beads only slightly disturbed the spores on the steel block (Pl. 2, fig. 4), but on dises (Pl. 2, fig. 5) they re-arranged the spores, although without clearing the impact area (arrowed). The photograph also shows a smaller area cleared by the rebound impact of the bead, the track along which it rolled off the

Table 2. Estimated total catch (hundreds of spores) in $\mathbf{5 0}$ l. air samples before, during and after collisions with Lycopodium spore-coated surfaces

\begin{tabular}{|c|c|c|c|c|c|c|}
\hline \multirow[b]{2}{*}{ First series } & \multicolumn{3}{|c|}{ Steel block } & \multicolumn{3}{|c|}{$\begin{array}{c}\text { Celluloid disc } \\
\text { (without 'Cirrasol' } * \text { ) }\end{array}$} \\
\hline & $\begin{array}{c}\text { Before } \\
\text { dropping }\end{array}$ & $\begin{array}{l}\text { During } \\
\text { dropping }\end{array}$ & $\begin{array}{c}\text { After } \\
\text { dropping }\end{array}$ & $\begin{array}{c}\text { Before } \\
\text { dropping }\end{array}$ & $\begin{array}{l}\text { During } \\
\text { dropping }\end{array}$ & $\begin{array}{c}\text { After } \\
\text { dropping }\end{array}$ \\
\hline $\begin{array}{l}2.4 \mathrm{~mm} \text {. drops } \\
5.2 \mathrm{~mm} \text {. drops } \\
3.5 \mathrm{~mm} \text {. glass beads }\end{array}$ & $\begin{array}{l}2 \cdot 6 \pm 4 \cdot 7 \\
0 \cdot 2 \pm 0 \cdot 2 \\
2 \cdot 2 \pm 3 \cdot 9\end{array}$ & $\begin{array}{r}26 \cdot 0 \pm 22 \cdot 7 \\
163 \cdot 4 \pm 64 \cdot 7 \\
4 \cdot 1 \pm 2 \cdot 6\end{array}$ & $\begin{array}{l}0 \cdot 3 \pm 0 \cdot 2 \\
0 \cdot 3 \pm 0 \cdot 4 \\
0 \cdot 3 \pm 0 \cdot 3\end{array}$ & $\begin{array}{l}0 \cdot 7 \pm 0 \cdot 6 \\
3 \cdot 0 \pm 7 \cdot 2 \\
2 \cdot 1 \pm 4 \cdot 4\end{array}$ & $\begin{array}{r}13 \cdot 3 \pm 19 \cdot 8 \\
126 \cdot 9 \pm 85 \cdot 0 \\
32 \cdot 1 \pm 17 \cdot 5\end{array}$ & $\begin{array}{l}0 \cdot 4 \pm 0 \cdot 6 \\
1 \cdot 0 \pm 1 \cdot 7 \\
1 \cdot 2 \pm 2 \cdot 5\end{array}$ \\
\hline & & & & \multicolumn{3}{|c|}{$\begin{array}{l}\text { Celluloid dise } \\
\text { (with 'Cirrasol') }\end{array}$} \\
\hline Second series & & & & $\begin{array}{c}\text { Before } \\
\text { dropping }\end{array}$ & $\begin{array}{l}\text { During } \\
\text { dropping }\end{array}$ & $\begin{array}{c}\text { After } \\
\text { dropping }\end{array}$ \\
\hline $3.0 \mathrm{~mm}$. drops & - & - & - & $0 \cdot 4 \pm 0 \cdot 1$ & $3 \cdot 3 \pm 5 \cdot 5$ & 0 \\
\hline $5.0 \mathrm{~mm}$. drops & 一 & - & 一 & $04 \cdot \pm 0 \cdot 1$ & $17 \cdot 3 \pm 25 \cdot 1$ & $0.3 \pm 0.5$ \\
\hline $3.5 \mathrm{~mm}$. glass beads & - & - & - & $0 \cdot 2 \pm 0 \cdot 1$ & $14 \cdot 1 \pm 15 \cdot 0$ & $0 \cdot 1 \pm 0 \cdot 1$ \\
\hline
\end{tabular}

disc and a system of concentric zones formed by shock waves travelling within the disc. On discs, drops of both sizes showed evidence of a fast radial splashing. The abrupt and toothed edge of the zone cleared by a $3.0 \mathrm{~mm}$. drop (Pl. 2, fig. 6) suggests that either the splash cup was flatter or the radial wind less intense than with a larger (5.0 mm.) drop (Pl. 2, fig. 7). Within the cleared area both sizes of drop showed dense (white) accumulations of spores which had been wetted. When the surface dried, these adhered to the celluloid much more than dry spores, as shown by Pl. 2, fig. 8, where a disc exposed to a $5 \cdot 0 \mathrm{~mm}$. drop was inverted and tapped to remove the dry spores. Both Pl. 2, figs. 6 and 7, show a peripheral zone where some air-transported dry spores from within the cleared area have been re-deposited. This zone is best defined with the larger drop (Pl. 2, fig. 7) where microdensitometer measurements showed that it reached about $1 \frac{1}{2}$ times the uniform density of spores. This halo is scarcely discernible around the impact area of $5.0 \mathrm{~mm}$. drops on the steel block, probably because the inelastic surface produces stronger radial flows which carry the spores beyond the immediate halo area (Pl. 2, fig. 9). The numerical and photographic evidence combine to support the theory that both shaking and radial flow can be important in suspending dry spores in the air when water-drops strike dry surfaces. It remains to show how often they are. 


\section{Tests with fungi}

Several fungi on plant material were tested to find whether collisions liberate spores. Where possible the tests were standardized, normally drops of $3.2 \mathrm{~mm}$. diam. were used, 10 collisions were observed per test and 5 replicate tests were made. It was not possible to standardize the plant material, the density of spores it bore or the way it was supported during exposure to collisions. It seems best therefore to comment individually on the fungi listed in Table 3.

\section{Phytophthora infestans-on potato leaves}

Records from spore traps in infected potato crops do not indicate increased concentrations of spores in the air at the start of rain; indeed decreases are usual (Hirst, 1958). Special care was taken in testing $\boldsymbol{P}$. infestans because we find that rapid humidity changes can release sporangia. Leaves with necrotic lesions $2-3 \mathbf{c m}$. diam. were collected in the evening and their petioles placed in water-filled specimen tubes taped to the inside walls of the 'sampling cylinders', which were closed, kept damp and shaded until after testing the following morning. (To minimize disturbance the impactor was inserted through the 2 in. hole in the top cover.) Separate specimens were used for each test or attitude. Collisions caused a small but definite increase in the number of spores released.

Pseudoperonospora humuli-on hop leaves

The leaves used came from plants grown in pots and kept moist in plastic bags until immediately before use; their petioles were fixed in modelling clay, which was stuck to the inner wall of the sampling cylinder so that the leaf attitude was either natural or inverted. Some spore release was expected without any water-drop collision, because the leaves had just been removed from a humid chamber to one into which dry air was continuously drawn (19 air changes occurred in the sampling cylinder every $5 \mathrm{~min}$.). These spores are entirely restricted to the under surface (abaxial surface) of the leaves and more were caught from leaves in their natural attitude than from other leaves which were inverted. This is probably because spores were able to fall clear of their sporangiophores and the leaf surfaces when oriented naturally and so had a much greater chance of dispersal.

When drops struck the spore-free upper surface of leaves in their natural attitude, a small, black, eddying cloud issued from below the impact point. This is probably unique among these tests as the only time dry spores were liberated entirely as a result of shaking by water-drop collisions. Although the tests with leaves in natural attitudes produced more spores, the ratio between the catches of the before-, during- and after-dropping samples $(1: 4.9: 0 \cdot 4)$ was low compared to that $(1: 50 \cdot 1: 1 \cdot 1)$ when the leaves were inverted and the collisions occurred on the sporebearing 'under' (abaxial) surface. Presumably, this was because shaking was then accompanied by radial air-flow able both to liberate and disperse spores and almost to counteract the effect of inverting the leaves.

Peronospora parasitica-on stems and capsules of Capsella bursa-pastoris

The response to dropping was much larger than with $P$. infestans. The stems were laid horizontally, without fixing, on cards placed on short mown grass. 


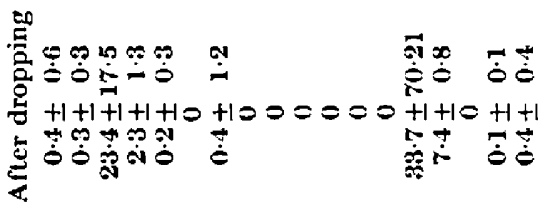

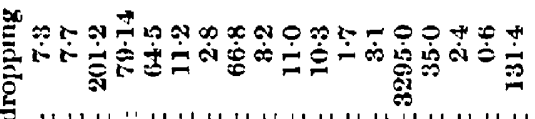
$2 x+1+1-1+1+1+1+1+1+1+1+1+1+1+1+1+1+1$

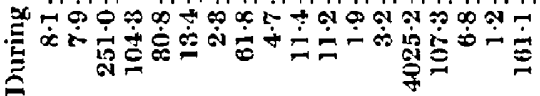

胥

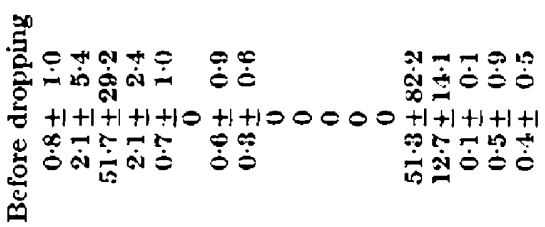

更

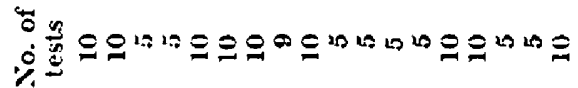

$\dot{g} \bar{g}$

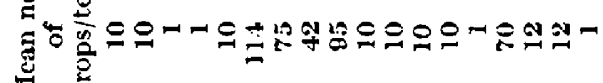

起

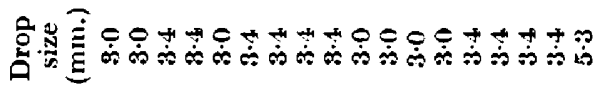

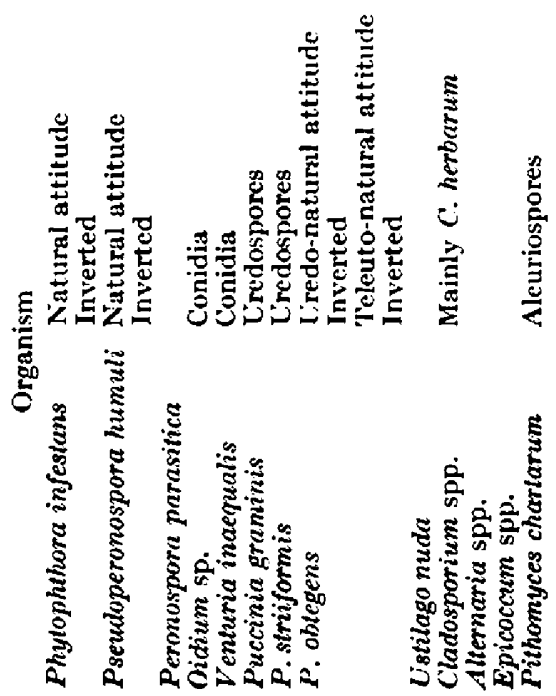


Oidium spp. (probably Erysiphe cichoracearum) on potato leaves

Chains of conidia formed on the upper leaf surfaces were dispersed by water-drop collisions. These leaves were also laid on thin cards and placed on short mown grass.

Venturia inaequalis-on apple leaves stapled to light cards

Only a small response, perhaps because the conidia are formed on very short stout annellate conidiophores. There is no doubt that they are easily splash dispersed.

Puccinia graminis-on 3 in. lengths of rusted wheat straws stapled on cards placed on short mown grass

Many of the uredospores in sori are already detached from their stalks. The tests show a large response which agrees with field observations that rain often increases the concentration of uredospores in the air (Hirst, 1961).

Puccinia striiformis-as for $\mathbf{P}$. graminis but on leaves of wheat

The ratio between 'before-, during- and after-dropping catches' cannot be used for comparison with $\boldsymbol{P}$. graminis but the much smaller catch 'during-dropping' supports observations that airborne spore concentrations of $\boldsymbol{P}$. strüformis are seldom large, even among severely infected crops. It would be interesting to compare the uredospore production of these two fungi per unit area of pustule.

Puccinia obtegens-uredo and teleuto sori on the under surface of thistle leaves

Leaves were held in the sampling chamber as for $P$. humuli. Both leaf surfaces of each specimen were exposed to collisions, upper surfaces were exposed first in one half of the tests and lower surfaces first in the other. Collisions aided the release of both spore types regardless of leaf attitude.

Ustilago nuda-on infected wheat ears

Portions of smutted ear were laid, with rachis horizontal, on cards on short mown grass and each exposed to one collision. The large catch of spores before and after dropping reflect the ease with which these already-detached spores are dispersed, but there is no doubt that their release is much assisted by even a single water-drop collision.

Cladosporium spp., Alternaria spp. and Epicoccum spp.

Spores of these saprophytes were released from leaves of ripe wheat plants stapled on to thin cards and laid horizontally on the base of the sampling chamber. Cladosporium and Alternaria, where spores are raised above the leaf surface, respond more than Epicoccum which has sessile spores.

Pithomyces chartarum-propylene oxide-killed cultures on dead rye grass leaf

There was a clear response to collision but the targets were more exposed than might be usual for litter in the sole of pastures.

Water-drop collisions on grass litter and short mown grass

Table 4 shows that Cladosporium concentration was increased several times by collisions with both medium and large drops. The same is probably true with 
Botrytis and Epicoccum; but the total catches were much smaller. The slight increase with Alternaria on grass contrasts with its behaviour on wheat leaves and may indicate that it was infrequent on the litter samples tested.

\section{Effect of drop size}

Tests with a range of drop sizes on the release of three saprophytic genera from leaves of ripe wheat always showed increasing numbers of spores liberated as the size of drops increased. With Cladosporium $\log n+1$ spores of the total estimated catch was significantly correlated with drop size (Table 5).

Table 4. Estimated total catch (hundreds of spores) in $\mathbf{5 0}$ l. air samples taken before, during and after water-drop collisions indicated

\begin{tabular}{|c|c|c|c|c|c|c|}
\hline Organism & $\begin{array}{c}\text { Drop } \\
\text { size } \\
\text { (mm. } \\
\text { diam.) }\end{array}$ & $\begin{array}{l}\text { Mean } \\
\text { no. of } \\
\text { drops } \\
\text { per test }\end{array}$ & $\begin{array}{c}\text { No. of } \\
\text { tests }\end{array}$ & $\begin{array}{c}\text { Before } \\
\text { dropping }\end{array}$ & $\begin{array}{l}\text { During } \\
\text { dropping }\end{array}$ & $\begin{array}{c}\text { After } \\
\text { dropping }\end{array}$ \\
\hline \multicolumn{7}{|c|}{ Collisions on grass litter } \\
\hline \multirow[t]{2}{*}{ Cladosporium spp. } & $3 \cdot 0$ & 36 & 6 & $169 \cdot 2 \pm 214 \cdot 6$ & $647 \cdot 1 \pm 726 \cdot 9$ & $10 \cdot 8 \pm 6 \cdot 6$ \\
\hline & $5 \cdot 3$ & 33 & 4 & $79.3+99.9$ & $1062 \cdot 1+1954 \cdot 0$ & $4 \cdot 1 \pm 5 \cdot 2$ \\
\hline \multirow[t]{2}{*}{ Botrytis cinerea } & $3 \cdot 0$ & 36 & 6 & $0.6+$ & $\mathbf{2} \cdot 0 \overline{+}$ & $0.1 \pm 0.2$ \\
\hline & $5 \cdot 3$ & 33 & 4 & $0.4 \pm$ & $3 \cdot 2 \pm$ & $0 \cdot 1 \pm 0 \cdot 1$ \\
\hline Alternaria spp. & $3 \cdot 0$ & 36 & 6 & $0 \cdot 2 \pm$ & $0 \cdot 4 \pm$ & $\overline{0}$ \\
\hline \multirow[t]{2}{*}{ Epicoccum spp. } & $3 \cdot 0$ & 36 & 6 & $0 \cdot 7 \pm$ & $1 \cdot 9 \pm$ & $0.1 \pm 0.5$ \\
\hline & $5 \cdot 2$ & 33 & 4 & $0.2 \pm \quad 0.5$ & $\mathbf{3} \cdot \mathbf{2} \pm$ & $0 \cdot 1 \pm 0 \cdot 1$ \\
\hline \multicolumn{7}{|l|}{ Collisions on short mo } \\
\hline Cladosporium spp. & $5 \cdot 3$ & 27 & 3 & $16 \cdot 7 \pm 26 \cdot 3$ & $76 \cdot 3 \pm$ & $36 \cdot 7 \pm 34 \cdot 2$ \\
\hline
\end{tabular}

Table 5. Effect of drop size: estimated total catch (hundreds) in 'during dropping' sample

\begin{tabular}{|c|c|c|c|}
\hline Drop size & Cladosporium & Alternaria & Epicoccum \\
\hline $2 \cdot 4$ & $91 \cdot 0 \pm 104 \cdot 7$ & $2 \cdot 1 \pm 0 \cdot 8$ & $1 \cdot 2 \pm 0 \cdot 6$ \\
\hline $\mathbf{3 \cdot 0}$ & $111 \cdot 8 \pm 51 \cdot 0$ & - & - \\
\hline $3 \cdot 2$ & $461 \cdot 3 \pm 294 \cdot 8$ & $6 \cdot 8 \pm 2 \cdot 4$ & $2 \cdot 0 \pm 2 \cdot 3$ \\
\hline $5 \cdot 2$ & $1356 \cdot 0 \pm 32 \cdot 4$ & $25 \cdot 7 \pm 9 \cdot 4$ & $3 \cdot 2 \pm 2 \cdot 4$ \\
\hline $\begin{array}{c}\text { Correlation coeff. ' } r \text { ' } \\
P\end{array}$ & $\begin{array}{l}+0.7618 \\
<0.001\end{array}$ & - & - \\
\hline
\end{tabular}

Regression equation of drop size on $\log n+1$ catch of Cladosporium $y=2 \cdot 567+0 \cdot 5124 x$.

\section{DISCUSSION}

Tests with Puccinia graminis and Lycopodium deposits showed that water-drop collisions suspended dry spores in air in addition to dispersing others in splash droplets. Raindrops can disperse dry spores in two ways, by mechanical shaking, and by radial air movements that can exceed 100 m.p.h. for very brief periods and short distances of travel. Sometimes one effect is dominant, sometimes the other, but probably both usually operate. To avoid confusing the several ways in which rain can influence the air spora it seems desirable to have a brief way of referring to these processes and we suggest they be known as 'rain tap and puff'.

There are many reasons why our attempts to standardize tests with the various organisms only partially succeeded. These include differences in the presentation of the spores for dispersal; variations in the 'background' count of the air drawn 
into the sampling cylinder (particularly important perhaps with Cladosporium); the great heterogeneity of the samples tested and differences in the directness of 'hits'; the degree to which spores were being liberated from the specimen in the sampling cylinder during tests, particularly important with Downy Mildews and Ustilago. These imperfections and the few replicate tests account for standard deviations of the same order as the means, but despite this inaccuracy there is seldom doubt that the collisions increased the catch. The smallest catch was usually in the 'after dropping' sample, presumably because much of the material was wetted and the supply of dry spores already partly exhausted. Comparisons of catches of different organisms and the ratio of before-, during- and after-dropping catches are often unreliable but usually support the expectation that the effect would be greatest with light dry spores already detached or borne at a distance from plant surfaces on structures from which they are easily sheared.

In addition to the published records and tests mentioned above, our spore trapping shows that the onset of rain at first increased but then decreased the concentration of many spore types including species of Cladosporium, Alternaria, Epicoccum, Botrytis, and Erysiphe graminis, Uromyces fabae, Puccinia graminis, P. strifformis, $P$. recondita and Ustilago nuda. The effect is particularly obvious with intense rain, when the proportion of large drops is great, but it is usually discernible in about half the rain periods. The resulting peak concentrations are often several times those occurring in dry weather, so they can contribute a large proportion of the total airborne spore load within crops. However, continued rain will soon wash many of the spores from the air, so the effect is likely to be important only in spreading diseases locally. Because rain can fall at any time, it can disperse at night spores that usually have a day-time maximum, thus producing favourable infection conditions with more chance of persisting than during the day. It is possible, but unestablished, that these processes contribute to the characteristic smell of newly wetted soil.

We wish to thank Miss Maureen Thomson for technical assistance, Mr F. D. Cowland for the photographs, Dr J. R. Coley-Smith of the Department of Hop Research, Wye College, for co-operation in the tests on Pseudoperonospora humuli and Mr J. Drew Smith of the Ruakura Animal Research Station, Hamilton, New Zealand, for co-operation with the tests on Pithomyces chartarum.

\section{REFERENCES}

Ainsworth, G. C. (1952). The incidence of air-borne Cladosporium spores in the London region. J. gen. Microbiol. $7,358$.

Davies, R. R. (1961). Wettability and the capture, carriage and deposition of particles by raindrops. Nature, Lond. $191,616$.

EngEL, O. G. (1955). Waterdrop collisions with solid surfaces. J. Res. Nat. Bur. Standards, 54, 281.

Gregory, P. H. (1954). The construction and use of a portable volumetric spore trap. Trans. Brit. mycol. Soc. 37, 391.

Gregory, P. H., Guthrie, E. J. \& Bunce, M. E. (1959). Experiments on splash dispersal of fungus spores. J. gen. Microbiol. 20, 328.

Hirst, J. M. (1953). Changes in atmospheric spore content: Diurnal periodicity and the effects of weather. Trans. Brit. mycol. Soc. 36, 375.

Hirst, J. M. (1958). New methods for studying plant disease epidemics. Outlook on Agric. 2, 16. 
Hirst, J. M. (1959). Spore liberation and dispersal. Plant Pathology: Problems and Progress 1908-1958, pp. 529-38. University of Wisconsin Press.

Hirst, J. M. (1961). The aerobiology of Puccinia graminis uredospores. Trans. Brit. mycol. Soc. 44, 138.

IngOLD, C. T. (1953). Dispersal in Fungi, pp. 197. Oxford: Clarendon Press.

Liddell, H. F. \& WootTen, N. W. (1957). The detection and measurement of water droplets. Quart. J. R. met. Soc. 83, 263.

MAY, F. G. (1958). The washout by rain of Lycopodium spores. AERE HP/R 2198, Atom. Energy Res. Establ., Harwell, Berkshire.

Meredith, D. S. (1962). Some components of the air-spora in Jamaican banana plantations. Ann. appl. Biol. 50, 577.

Rich, S. \& WagGoner, P. E. (1962). Atmospheric concentration of Cladosporium spores. Science, 137, 962.

Sreeramulu, T. (1962). Aerial dissemination of barley loose smut (Ustilago nuda). Trans. Brit. mycol. Soc. 45, 373.

\section{EXPLANATION OF PLATES}

\section{Plate 1}

Fig. 1. Tripod ladder with central dropping tube.

Fig. 2. Sampling cylinder and spore trap in position at base of dropping tube.

\section{Plate 2}

Fig. 3. Photomicrograph of portion of 'half-coated trap slide'. Above: portion where wet and dry spores are impacted on 'Vaseline'. Below: water droplet traces containing few uredospores on the area coated with Naphthol Green $B$ in gelatine (see text).

Figs. 4-9. Photographs of Lycopodium spore deposits after exposure to single collisions. Fig. 4. Deposition on steel block exposed to one glass bead impact. Fig. 5. The same impact but on 'Celluloid' disc; note original strike (arrowed), rebound strike and track of bead rolling off the disc. Fig. 6. Result of $3.0 \mathrm{~mm}$. drop falling on disc. Fig. 7. Result of $5.0 \mathrm{~mm}$. drop falling on disc. Fig. 8. Deposit, similar to that in Fig. 7, after inversion and tapping, showing how spores are retained only where wetted, i.e. in peripheral splash droplets and central irregular area, into which residual water in impact area contracted. Fig. 9 . Result of $5.0 \mathrm{~mm}$. drop falling on block. 


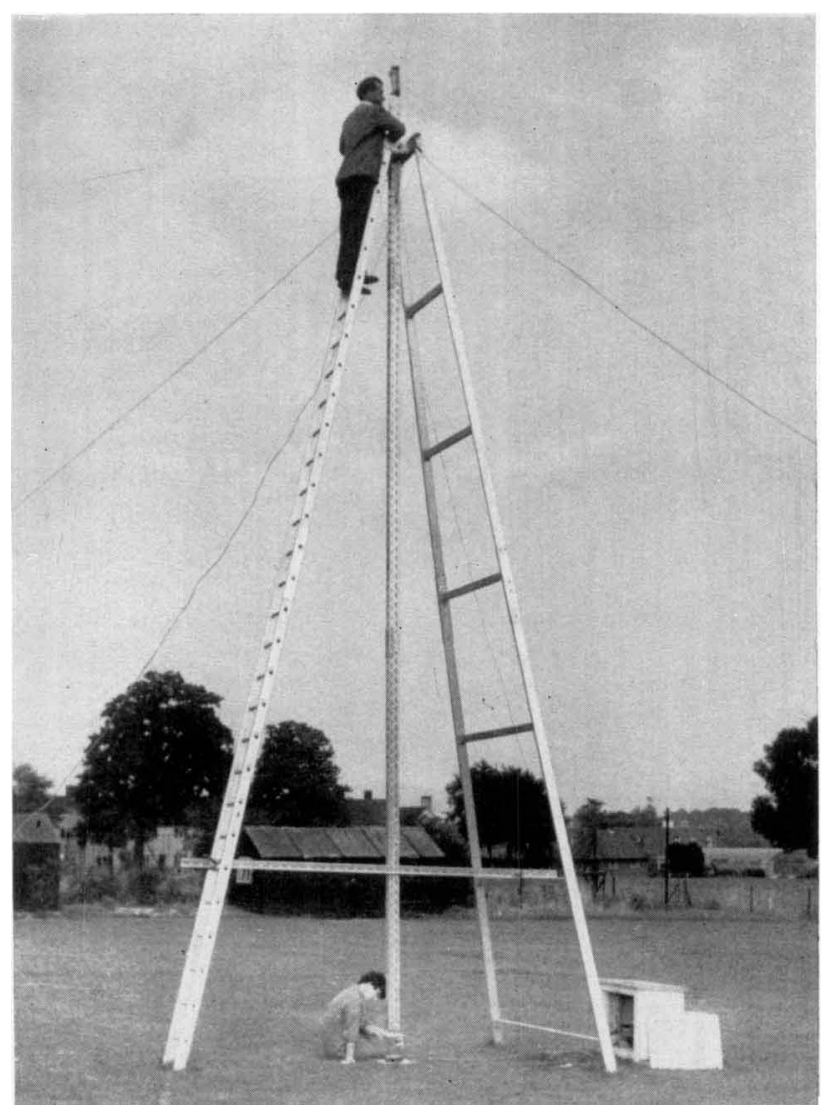

Fig. 1

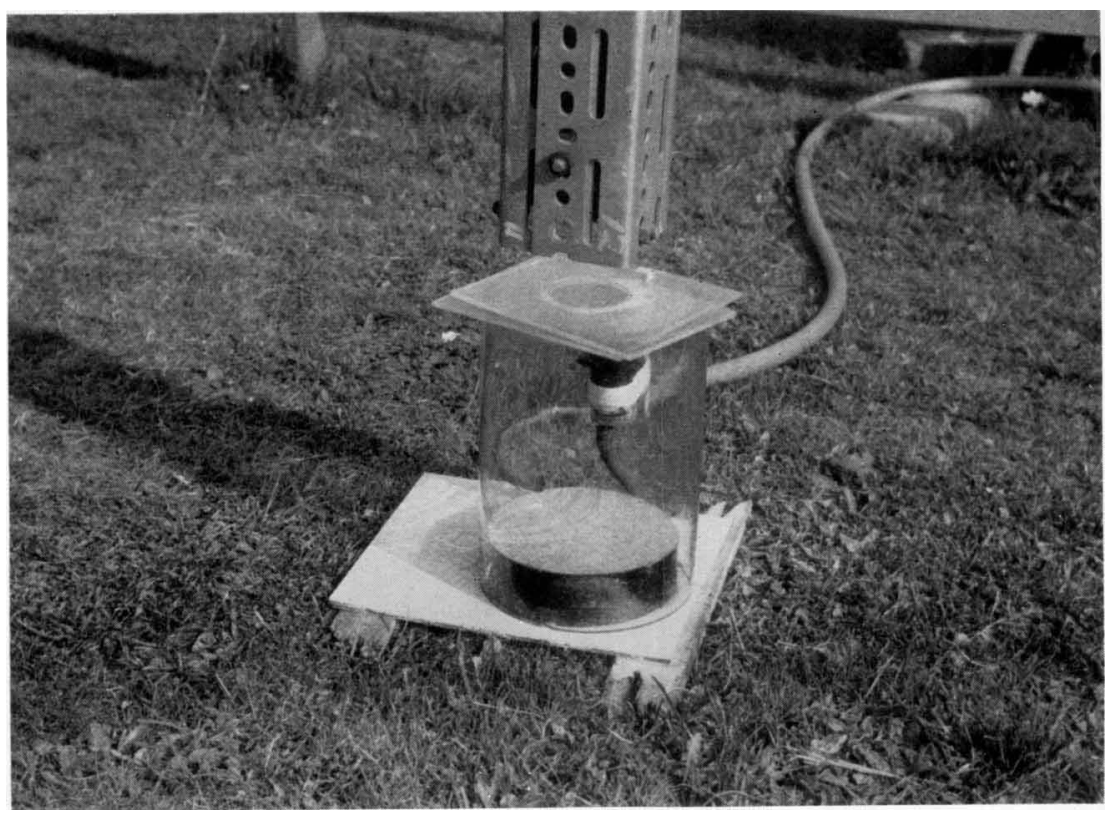

Fig. 2 
Journal of General Microbiology, Vol. 33, No. 2

Plate 2

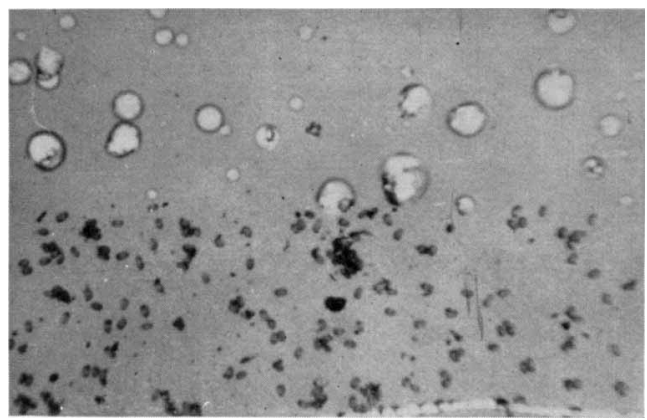

Fig. 3

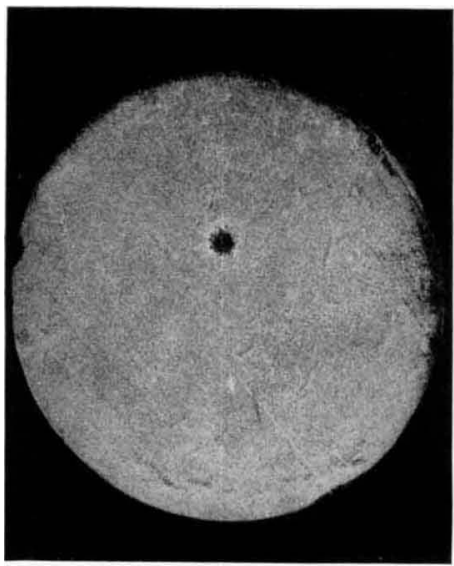

Fig. 4

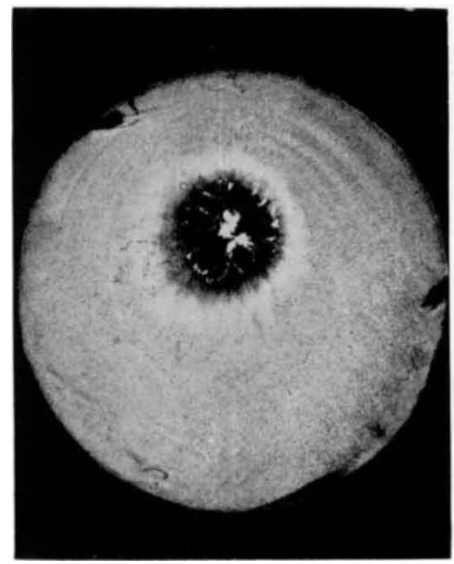

Fig. 7

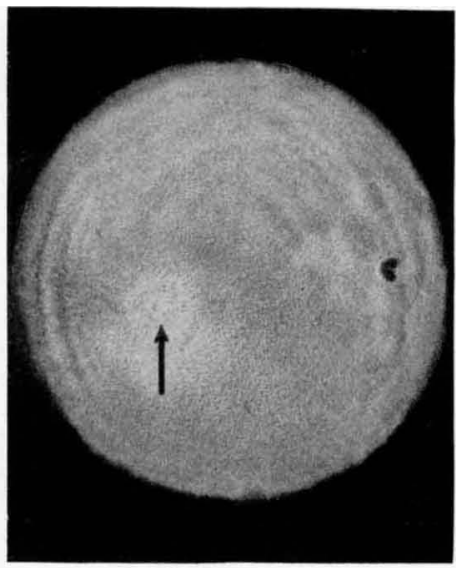

Fig. 5

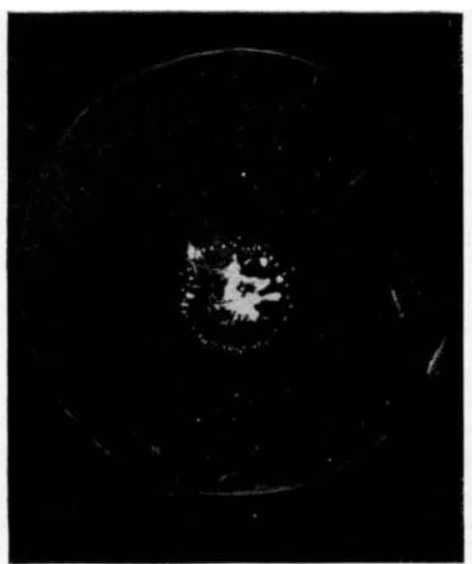

Fig. 8

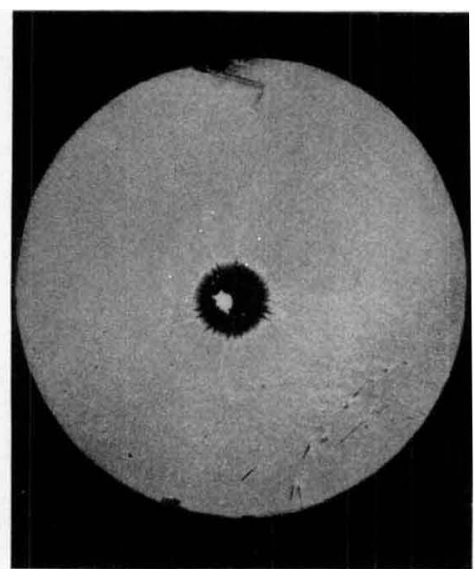

Fig. 6

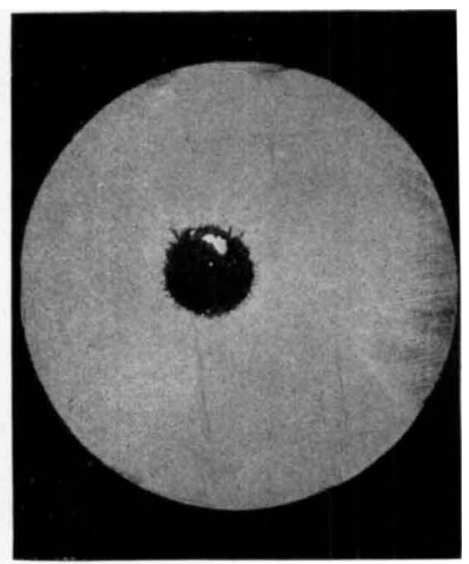

Fig. 9

J. M. HIRST AND O. J. STEDDMAN 